\title{
Networking of Smart Meters Based on Time-Varying Feature of Low-Voltage Power Line Channel in Microgrid
}

\author{
Ya-Xin Huang $\mathbb{D}^{1},{ }^{1}$ Xiao-Di Zhang $\mathbb{D}{ }^{2}$ Fei Yu, ${ }^{1}$ Yong-Qing Wei, ${ }^{1}$ and Hai-Long Zhang ${ }^{3}$ \\ ${ }^{1}$ College of Electrical Engineering, Naval University of Engineering, Wuhan 430072, China \\ ${ }^{2}$ State Grid Beijing Electric Maintenance Company, Beijing 100080, China \\ ${ }^{3}$ General Construction Company of CCTEB Group Co., Ltd., Wuhan 430064, China \\ Correspondence should be addressed to Ya-Xin Huang; haizhixina@126.com
}

Received 21 November 2020; Revised 29 December 2020; Accepted 15 January 2021; Published 29 January 2021

Academic Editor: Xin Li

Copyright ( 2021 Ya-Xin Huang et al. This is an open access article distributed under the Creative Commons Attribution License, which permits unrestricted use, distribution, and reproduction in any medium, provided the original work is properly cited.

In order to manage the electricity consumption information of microgrid users, the reliability of electricity information collection is studied in this paper. The normal communication between the acquisition terminal and the smart meter is a key factor affecting the accurate collection of power information; it is the basis for ensuring the operation of the microgrid as well. In order to improve the reliability of the low power line communication between the acquisition terminal and smart meters, this article first uses the static networking method to layer the smart meters and select relays from them and then select the optimal communication path based on integrating communication quality and relay forwarding number dynamically, which could avoid the signal conflict problem caused by simultaneous communication. Finally, by analyzing the influence of the time-varying power line channel on the smart meter communication, a method based on the integrated communication quality and the relay number to consider the time variability of low power line communication is proposed. Choosing the optimal path of the smart meters when the communication path is abnormal can not only establish a new communication path for communication in time, but also avoid communication failures caused by the time-varying channel. Through MATLAB simulation, the time-varying dynamic network of the power line channel is introduced in this paper, which improves the reliability of the smart meter communication and has certain guiding significance for the actual smart meter network construction in microgrid.

\section{Introduction}

1.1. Background. In recent years, with the widespread application of renewable energy and the continuous reduction of the energy storage equipment costs, various forms of DC microgrid have emerged. Driven by power electronics technology and energy storage technology including solar, wind, microturbines, and batteries $[1,2]$, DC microgrid has been developed rapidly. Figure 1 is a schematic diagram of microgrid structure, which includes wind power, solar power, diesel generator, microturbines, and other power sources [3]. With its advantages of easy control, high reliability, and low energy consumption, DC microgrid will become the main power supply structure in remote mountain village and future households $[4,5]$. Therefore, how to manage the power consumption of these distributed DC microgrids has become a problem that needs to be solved in the power industry. Smart meter is one of the basic devices for data acquisition of smart grid. It undertakes the tasks of data acquisition, measurement, and transmission of original electric power [6], and it is the basis of information integration, analysis, and optimization, as well as information presentation. According to the country's 13th Five-Year Plan, China will fully enter the "power grid 2.0" in 2020, achieving $100 \%$ coverage of smart meters. Therefore, accurate data information collection of smart meters is of great significance to the construction of microgrid.

1.2. Motivation. Traditionally, compared to AC microgrid via event-triggered communication [7], power line communication (PLC) has been widely employed in several microgrid application areas, e.g., for the automation of the power grid [8], for the connection of smart meters [9] (as an 


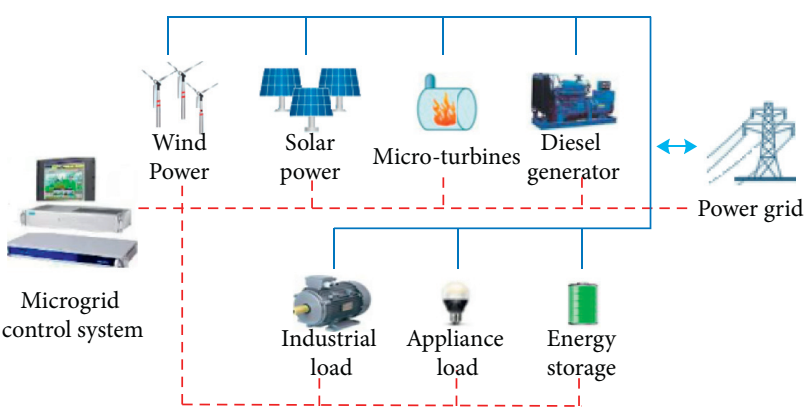

FIgURE 1: The schematic diagram of microgrid structure.

alternative to wireless connection [10]), and for home automation connected with smart appliances [11].

In practical applications, because the power line has the advantages of wide coverage, low cost, and high transmission speed, it is often used for information acquisition and transmission of smart meters [12]. However, since the power line communication has the characteristics of large signal attenuation, uneven signal distribution, and multipath effects $[13,14]$, as the communication distance increases, communication failures or anomalies will lead to information collection failures or abnormalities $[15,16]$. According to statistics, only $96 \%$ of smart meters can accurately collect information [17]. Once the communication between the acquisition terminal (the concentrator) and the smart meter is abnormal, it will not only affect the accuracy and timeliness of the collection data, but also pose a certain threat to the stable operation of the microgrid. Therefore, improving the reliability of smart meter power line communication is of great significance to the intelligent construction of microgrid power supplies.

1.3. Literature Survey. At present, there are two methods to improve the reliability of power line communication. The first method is to increase the probability of correct point-topoint communication. Second, some scholars and manufacturers have begun to focus on the use of network routing (relay) to improve the reliability of power line communication networks.

In order to improve the accuracy of the point-to-point communication, literatures [18-23] mainly studied the PLC performance evaluations based on attenuation and noise models (e.g., additive white Gaussian noise (AWGN), impulse noise, and narrowband interference). The previous low-voltage power line networking technology in $[24,25]$ is based on artificial spider algorithm, $[26,27]$ are based on clustering method, $[28,29]$ are based on ant colony algorithm, and [30-32] are based on genetic algorithm, just for increasing the communication distance between the acquisition terminal and the smart meters. In experiments, the time-varying characteristics of lowvoltage power lines have an important influence on the transmission distance of data signals. These networking technologies do not take the time-varying characteristics into account.
1.4. Contribution. A static and dynamic networking method is proposed to avoid the problem of signal conflict when smart meters are used as relay.

The communication distance, relay number, and the time-varying characteristics of low-voltage power line channel are regarded as the main factors of the network, making the network more stable and reliable.

Based on the actual situation, the key parameters in the dynamic networking process are established, and the invulnerability is verified by simulation.

After simulation, when the communication caused by sudden access load on the original communication path is abnormal, a more reliable communication branch can be searched dynamically.

\section{The Power User Electric Energy Data Acquisition System}

2.1. Network Topology of Smart Meters. Under normal circumstances, the current power user electric energy data acquisition system in the low-voltage platform area consists of an acquisition terminal (concentrator as the acquisition terminal), a communication channel, and a master station system. Within the same transformer control area, the smart meter is connected to a concentrator via a power line, and the concentrator collects power consumption information on the smart meter through the power line; the concentrator transmits the collected power consumption information to the server through the metering system private network, as is shown in Figure 2. The client of power user electric energy data acquisition system can view the power consumption information of each smart meter at any time.

\subsection{Preconditions for Communication between the Concen-} trator and Smart Meters. Ideally, the concentrator could directly communicate with all smart meters in the same transformer distribution network, but due to noise interference, signal attenuation, multipath effects, and other factors in the low-voltage power line channel, the communication distance between the concentrator and the smart meters is limited. In fact, according to experiments, the communication distance between the concentrator and the smart meter is 200 meters to 400 meters. According to [33], the communication distance between smart meters is about 30 meters. When the communication distance between the concentrator and the smart meter exceeds this range, direct communication cannot be established between them. Therefore, in order to realize normal communication between the concentrator and the long-distance smart meters, the smart meters need to be networked; that is, suitable relays are selected between the concentrator and the remote smart meters. The relay has the function of forwarding concentrator instructions and could forward messages from the concentrator to remote smart meters that cannot directly communicate with the concentrator.

2.3. The Function of Concentrator and Smart Meters. The concentrator not only has a function of collecting smart 


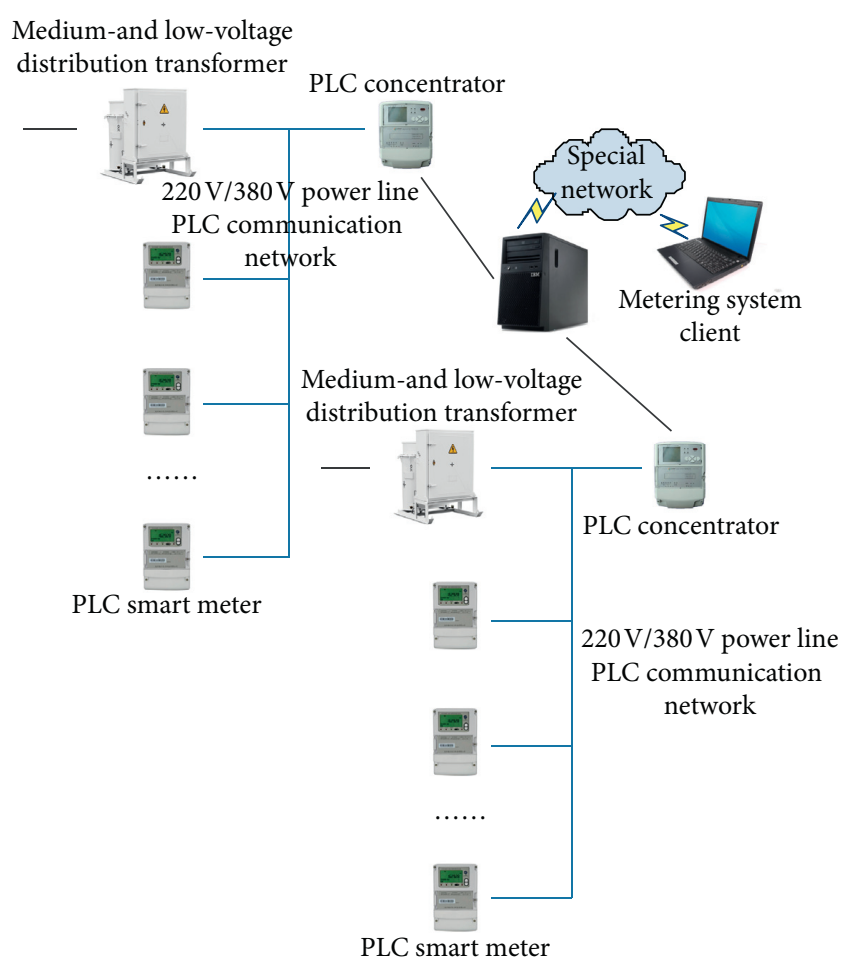

FIgURE 2: The schematic diagram of user information acquisition system.

meter information, but also has many other functions. Its specific function configuration is shown in Table 1 .

In addition to the traditional power metering function, the smart meters also have a two-way data communication function, with multiple data transmission modes [34] and the relay function. In order to establish the communication between the concentrator and the remote smart meter, it is necessary to select the appropriate smart meter as the relay, and the smart meter selected as the relay can forward the message to the remote smart meter. The communication schematic diagram is shown in Figure 3.

\section{Static Relay Selection}

3.1. Static Relay Selection Method. In this paper, the smart meter that could be used as a relay is firstly selected by a static method referring to [35]. The schematic diagram of selecting the relay for each layer is shown in Figure 4. Search for hierarchy selection from the first layer sequentially, for example, as the first-level relay that can directly communicate with the concentrator, and the smart meters that communicate with the first-level relay are placed in the first layer. In order to avoid communication failures caused by signal conflicts, there is no communication between smart meters of the same level. When smart meters belonging to the first level can communicate with a non-first-level smart meter, the smart meter belonging to the first level is placed in the second-level subnet and serves as a second-level relay. The selection of the relays for other layer subnet is performed in this order; that is, when the upper-level smart meter can communicate with the lower-level smart meter, the upperlevel smart meter is used as the lower-level relay.
According to the static relay selection method described above, static relay selection is performed on the logical topology of the smart meter in the experimental area. Figure 5 is a logical topology after the static relay is selected, wherein smart meters of the same color belong to the samelevel subnet.

3.2. Problems after Static Relay Selection. The problem with the static relay selection method is that the same common smart meter belongs to the communication range of multiple superior relays at the same time. If multiple relays forward messages to the same smart meter at the same time, signal conflicts will occur, resulting in communication failure, as is shown in Figure 6; the blue nodes are smart meters belonging to multiple superior relays. With reference to the logic topology after static relay selection in Figure 5, each smart meter could establish communication with the concentrator, but since some smart meters belong to multiple relay communication ranges at the same time, if multiple relays forward the packets of the concentrator to the same smart meter at the same time, there will be a signal conflict that causes communication failure.

For example, refer to Figure 4, the no. 11 relay within the communication ranges of no. 7 and no. 15 relays. When the two relays communicate with the no. 11 relay at the same time, the no. 11 relay will not be able to transmit information to the concentrator at time. In actual network communication, with the increase of smart meters, the communication network will become more complex, and the channel capacity and signal conflict will become more and more obvious, which cannot be ignored. Therefore, when a smart 
TABLE 1: Concentrator function configuration.

\begin{tabular}{|c|c|c|}
\hline Sequence number & & \\
\hline 1 & Data acquisition & Data acquisition of smart meter \\
\hline 2 & Data management and storage & $\begin{array}{c}\text { Real-time data and current data } \\
\text { Historical date data } \\
\text { Historical month data } \\
\text { Key user acquisition }\end{array}$ \\
\hline 3 & Parameter setting and query & $\begin{array}{c}\text { Clock call and timing } \\
\text { Terminal parameters } \\
\text { Meter reading parameters } \\
\text { Other (limit, prepaid, etc.) parameters }\end{array}$ \\
\hline 4 & Event $\log$ & $\begin{array}{l}\text { Record of important events } \\
\text { General event record }\end{array}$ \\
\hline 5 & Data transmission & $\begin{array}{c}\text { Communication with main station } \\
\text { Data forwarding }\end{array}$ \\
\hline 6 & Local function & $\begin{array}{c}\text { Run indication } \\
\text { Local maintenance interface }\end{array}$ \\
\hline 7 & Terminal maintenance & $\begin{array}{l}\text { Self-checking and self-recovery } \\
\text { Terminal initialization } \\
\text { Software remote download } \\
\text { Resume from break point }\end{array}$ \\
\hline
\end{tabular}

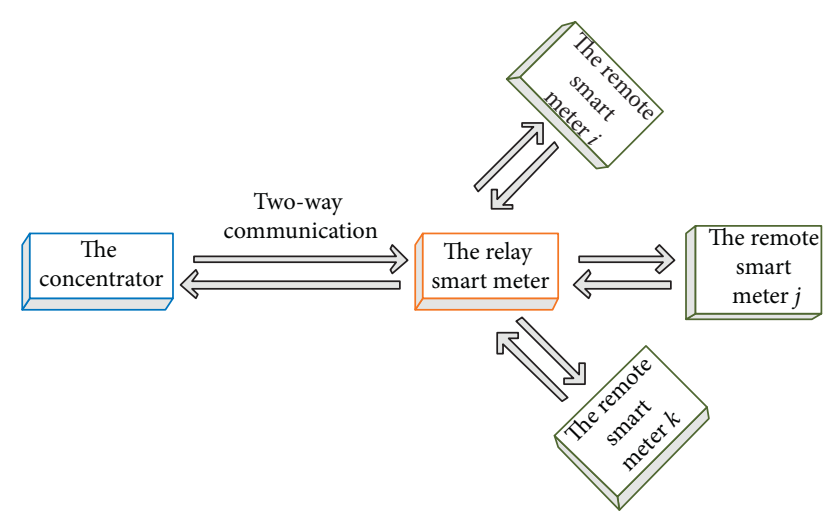

FIGURE 3: The communication diagram of the remote smart meters.

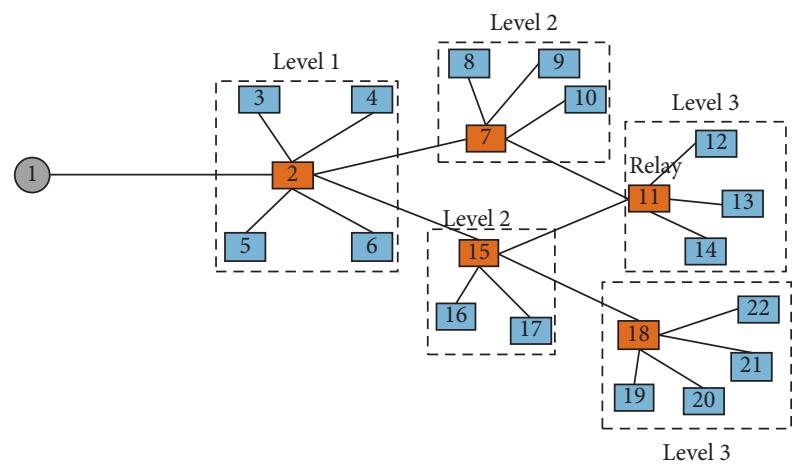

1) Concentrator

Smart meter

Relay

FIgURE 4: The schematic diagram of static relay selection.

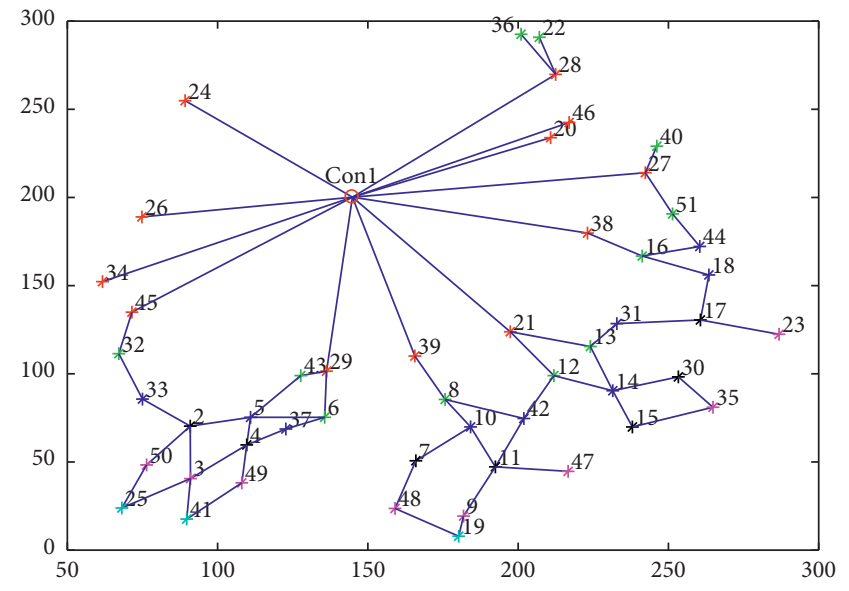

Figure 5: Logical topology after static relay selection.

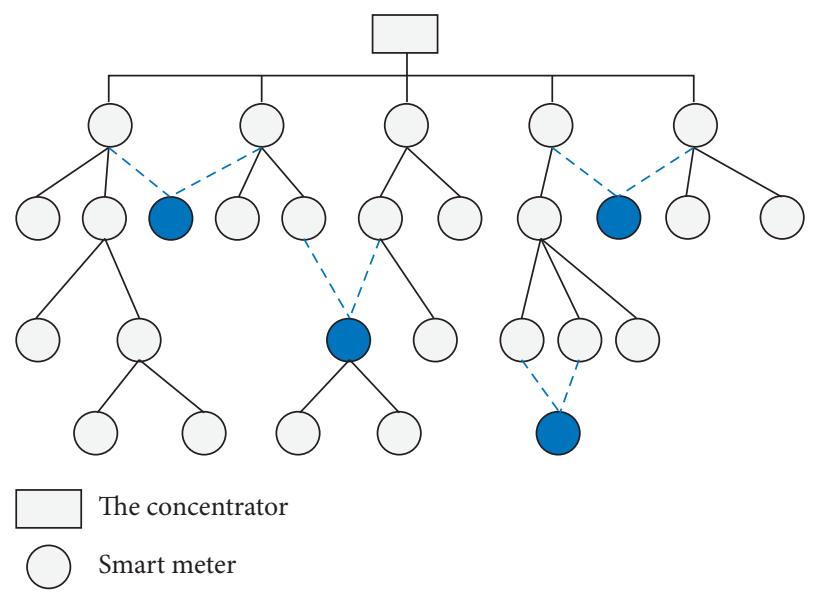

Figure 6: Schematic diagram of logical topology for signal collisions. 
meter belongs to multiple superior relays at the same time, finding the optimal relay and communication with it is the key to microgrid network networking.

\section{Time-Varying Analysis of Power Line Channels}

In microgrid, in order to improve the communication between smart meters and the concentrators, after static relay selection, dynamic relay is also required. There are two main functions of the dynamic relay: the first is to select the best communication path according to the objective function when the remote smart meter to be collected is within the communication range of two or more relays, and the second is to select the other path to communicate dynamically when the data information collected by the concentrator is abnormal. At present, although the cobweb algorithm in the literature proposes a solution when the original communication branch communicates abnormally, it just randomly selects another path without considering the time-variation of the power line channel. In practice, the concentrator collects the data information every 15 minutes from each smart meter. According to the time-varying analysis of the power line channel, it was found that the original communication path has abnormal information at the previous moment, but after 15 minutes, the communication may be restored to normal. Therefore, the time-varying power line channel is one of the key factors affecting the reliability of low-voltage power line communications. When dynamic relay selection is performed, time-varying power line channel needs to be considered.

4.1. Time-Varying Property of Power Line Channel. When a smart meter acts as a relay for forward packets, the random access of the user's load will affect the normal communication of the power line channel. Therefore, referring to the impedance characteristics of 36 lowvoltage power systems at the frequency of $0.2-30 \mathrm{MHz}$, the attenuation characteristics of the typical low-voltage distribution network at frequencies of $0-500 \mathrm{kHz}$ [36], the frequency response of the indoor low-voltage power line channel characteristics [37], and the measurement of channel impedances in [38], this paper mainly analyzes the impact of impedance time-varying on power line channels. In order to facilitate the analysis of channel transmission characteristics when accessing different loads, the transmission line system is regarded as a twoport network according to Galli and Banwell [39], and power line channels are modeled for different network structures and loads.

4.2. Transmission Line Model. According to transmission line theory [40], signals are transmitted in the form of transverse electromagnetic waves (TEM) in the power line. When current is transmitted through two wires, a constantly changing magnetic field appears around the wire. Due to the continuous change of the magnetic field, the induced voltage will cause the voltage change between the wires, and the leakage current between the wires will increase with the increase of voltage and frequency [37]. Therefore, the uniform transmission line model is used as a distributed circuit model composed of a series of components. The circuit diagram of the model is shown in Figure 7.

The characteristic impedance $Z_{0}$ and propagation coefficient $r$ of the transmission line are calculated according to the following formula:

$$
\left\{\begin{array}{l}
Z_{0}=\sqrt{\frac{R_{0}+j 2 \pi f \cdot L_{0}}{G_{0}+j 2 \pi f \cdot C_{0}}}, \\
r=\sqrt{\left(R_{0}+j 2 \pi f \cdot L_{0}\right)\left(G_{0}+j 2 \pi f \cdot C_{0}\right)}=\alpha+j \beta,
\end{array}\right.
$$

where $\alpha$ is the attenuation coefficient, which indicates the attenuation of the signal; $\beta$ is the phase shift coefficient, which indicates the phase change of the signal [41].

For ideal uniform power line, $R_{0}, L_{0}, G_{0}$, and $C_{0}$ can be calculated based on the following formula:

$$
\left\{\begin{array}{l}
R_{0}=\frac{2}{a} \sqrt{\frac{f u_{c}}{\pi \sigma_{c}}}, \\
L_{0}=\frac{u}{\pi} \ln \left(\frac{d+\sqrt{d^{2}+(2 a)^{2}}}{2 a}\right), \\
G_{0}=\frac{\pi \sigma}{\ln \left(\left(d+\sqrt{d^{2}+(2 a)^{2}}\right) / 2 a\right)}, \\
C_{0}=\frac{\pi \varepsilon}{\ln \left(\left(d+\sqrt{d^{2}+(2 a)^{2}}\right) / 2 a\right)},
\end{array}\right.
$$

where $a$ is the radius of the wire; $f$ is the frequency; $u_{c}$ is the magnetic permeability of the conductor; $\sigma_{c}$ is the conductivity of the conductor; $u$ is the permeability between the two wires; $\sigma$ is the conductivity between the two wires; $d$ is the distance between the two wires; and $\varepsilon$ is the dielectric constant between the wires.

Since the actual line resistance Rand the conductance Gvary with frequency, they are corrected by the following equation:

$$
\left\{\begin{array}{l}
R=R_{0} \cdot 10^{-5} \cdot \sqrt{f}\left(\frac{\Omega}{m}\right), \\
G=G_{0} \cdot 10^{-14} \cdot 2 \pi f\left(\frac{\Omega}{m}\right) .
\end{array}\right.
$$

Assuming that the transmission line is ideal, any uniform transmission line can be expressed in two-port network. According to the schematic diagram of the two-port model of Figure 8, the voltage and current relation of the two port is 


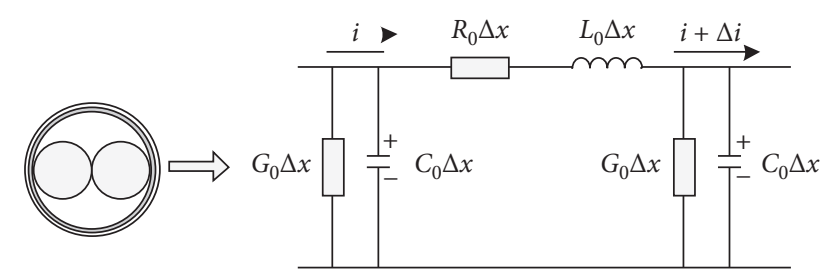

FIgURE 7: Equivalent circuit of uniform transmission line.

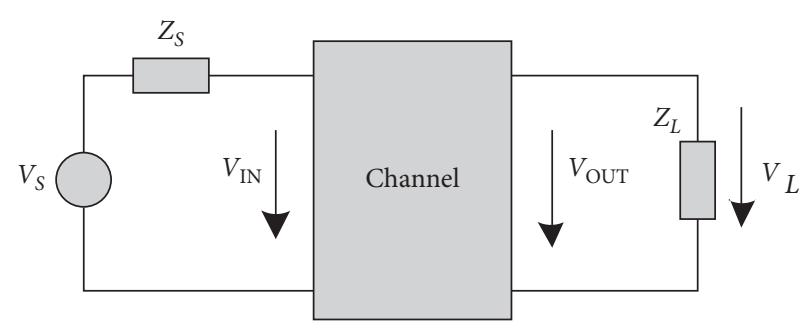

FIgURE 8: Two-port network schematic diagram.

$$
\begin{aligned}
& \left|\begin{array}{c}
V_{1} \\
I_{1}
\end{array}\right|=\left|\begin{array}{cc}
A & B \\
C & D
\end{array}\right|\left|\begin{array}{c}
V_{2} \\
I_{2}
\end{array}\right|=T_{f}\left|\begin{array}{c}
V_{2} \\
I_{2}
\end{array}\right|, \\
& \left|\begin{array}{l}
V_{2} \\
I_{2}
\end{array}\right|=\left|\begin{array}{ll}
A & B \\
C & D
\end{array}\right|-\left|\begin{array}{c}
V_{1} \\
I_{1}
\end{array}\right|=\frac{1}{A D-B C}\left|\begin{array}{cc}
D & B \\
C & A
\end{array}\right|\left|\begin{array}{c}
V_{1} \\
V_{2}
\end{array}\right|=T_{b}\left|\begin{array}{c}
V_{1} \\
I_{1}
\end{array}\right|,
\end{aligned}
$$

where $T_{f}$ is forward transmission matrix and $T_{b}$ is backward transmission matrix.

In Figure 8, the supply voltage is

$$
V_{s}=V_{1}+I_{1} Z_{s}
$$

Load voltage is

$$
V_{2}=I_{1} Z_{s}
$$

Input impedance is

$$
Z_{\text {in }}(f)=Z_{0} \frac{Z_{L} \cosh r l+Z_{0} \sinh r l}{Z_{0} \cosh r l+Z_{L} \sinh r l}=\frac{A Z_{L}+B}{C Z_{L}+D} .
$$

The legendary function of the two-port network is

$$
\begin{gathered}
H(f)=\frac{V_{2}}{V_{S}}=\frac{Z_{L}}{A Z_{L}+B+C Z_{S} Z_{L}+D Z_{S}}, \\
\left\{\begin{array}{l}
A=D=\cosh r l \\
B=Z_{0} \sinh r l \\
C=\frac{1}{Z_{0}} \sinh r l
\end{array} \rightarrow T_{f}=\left|\begin{array}{cc}
\cosh r l & Z_{0} \sinh r l \\
\frac{1}{Z_{0}} \sinh r l & \cosh r l
\end{array}\right|,\right.
\end{gathered}
$$

where $l, r$, and $Z_{0}$ are the length of conductor, transmission constant, and characteristic impedance of cable, respectively, and the parameter of $T_{f}$ satisfies $A=D$, $B \neq C$, and $A D-B C=1$ at any frequency.
4.3. Network Model. In order to establish the communication channel model more accurately, this paper analyzes the network structure of smart meters. In a typical lowvoltage distribution network, the lines connected to the trunk and branches are called distribution cabinets, and where the smart meter is generally installed. The branch line is directly connected to each branch plug. In the room, the branch plug is connected to the various sockets through the inner line, and the socket is directly connected to the load with different impedance characteristics. As shown in Figure 9, the trunk line is relatively thick, while the branch line is thinner.

In Figure 9, it can be seen that there is a star-type connection between the distribution cabinet and the branch plug, and there are star-type and bus-type connections between the branching plug and the outlets. In the star structure, the branch plug and the socket are directly connected, while the bus-type connection refers to the socket connected in parallel to one line. If the connection mode is a star connection, it is equivalent to the parallel connection of multiple loads at the node. For the bus connection mode, it is equivalent to the cascading mode of the load, and the specific size is the input impedance of the branch line.

The forward transmission matrix of the branch plug is

$$
T_{\mathrm{BT}}=\left|\begin{array}{cc}
1 & 0 \\
\frac{1}{Z_{\mathrm{in}}} & 1
\end{array}\right| .
$$

Calculate the input impedance $Z_{\text {in }}$ of the branch plug using equation (8).

For a given network, this paper uses a transmission matrix to build a channel model. The total transmission matrix of a star connection can be obtained by cascading, as shown in the following equation:

$$
T_{f}=T_{f}^{(1)} \cdot T_{f}^{(2)} \cdots \cdots T_{f}^{(N)}
$$

where $T_{f}$ is a forward transmission matrix of a network composed of $N$ parts and $T_{f}^{(N)}$ is a forward transmission matrix of part $N$. The total backward matrix $T_{b}$ is

$$
\begin{aligned}
T_{b}=\left(T_{f}\right)^{-1} & =T_{f}^{(N)} \cdot T_{f}^{(N-1)} \cdots \cdots T_{f}^{(1)} \\
& =\prod_{i=1}^{N}\left[\begin{array}{ll}
A_{i} & B_{i} \\
C_{i} & D_{i}
\end{array}\right]=\left[\begin{array}{ll}
A & B \\
C & D
\end{array}\right] .
\end{aligned}
$$

4.4. Load Model. According to the characteristics of the load over time, it is divided into three categories: constant impedance, time-invariant frequency selective impedance, and time-varying frequency selective impedance. This paper sets the low impedance of the load to $5 \Omega$, the RF standard impedance to $50 \Omega$, the equivalent transmission line characteristic impedance to $150 \Omega$, and the high impedance to $1000 \Omega$. Since the access terminals of most electrical devices have interference capacitances, the impedance of the power line is resistive and inductive. Therefore, when the load connected to the power line is frequency-selective 


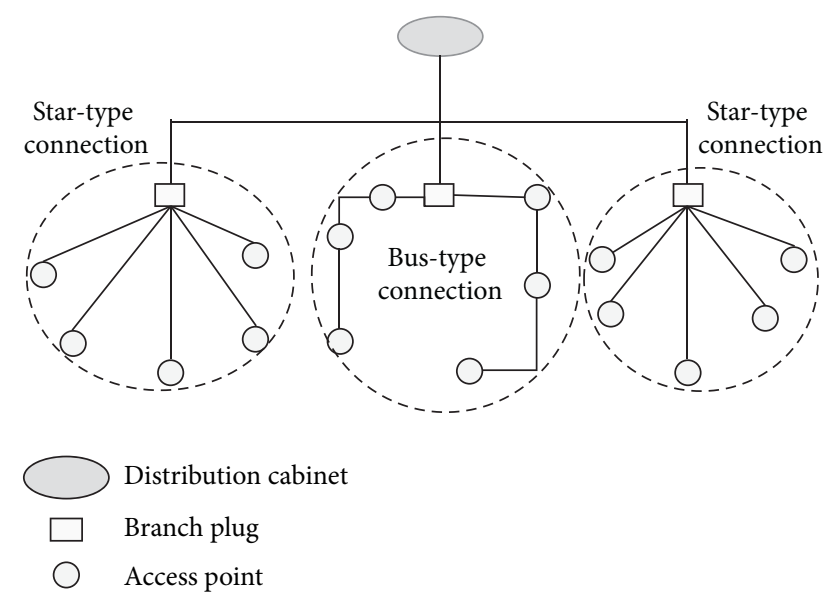

FIgURE 9: Network structure between smart meters.

impedance, it can be equivalent to an RLC series or parallel connection. Its impedance expression is shown in the following equation:

$$
\begin{aligned}
Z_{w} & =\frac{R}{1+j Q\left(\omega / \omega_{0}-\omega_{0} / \omega\right)}, \\
Z_{s}(w) & =R+j R Q\left(\frac{\omega}{\omega_{0}}-\frac{\omega_{0}}{\omega}\right),
\end{aligned}
$$

where $R$ is the resonant impedance, $\omega_{0}$ is the resonant frequency, and $Q$ is the quality factor. The setting range of load model parameters in this article is as follows: $R \in\{200,1800\} \Omega, Q \in\{5,25\}, \omega_{0} / 2 \pi \in\{1,30\} \mathrm{MHz}$.

According to the measurement results of the channel impedance [40], there are two main types of time-varying load impedances. One is to switch the load impedance value between two values. The other is that the load impedance changes synchronously with the power frequency cycle, and the impedance changes continuously over time. Its expression is shown in the following equation:

$$
Z(\omega, t)=Z_{A}(\omega)+Z_{B}(\omega)\left|\sin \left(\frac{2 \pi}{T_{0}} t+\phi\right)\right|, \quad 0 \leq t \leq T_{0},
$$

where $Z_{A}$ is the minimum value of the load impedance, $Z_{B}$ is the increment of the change of the impedance, and $\phi$ represents the relationship with the power frequency period, which could be considered to be evenly distributed during modeling.

4.5. Time-Varying Channel Modeling Verification and Analysis. According to the measurement data in [37], the distance between the power line of the plug and the socket is set to $20 \sim 50 \mathrm{~m}$, and the distance of the communicable power line between the smart meter and the smart meter is $1 \sim 30 \mathrm{~m}$.

According to the different connection modes of the load, the network structure between the two smart meters is equivalent to two forms: one is the star network structure in Figure 10, and the other is the bus-type network structure in Figure 11.

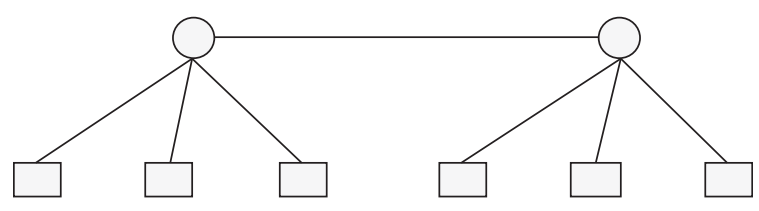

FIgURE 10: The star network structure.

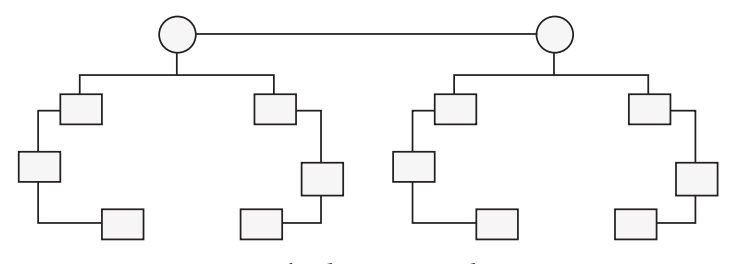

FIgURE 11: The bus network structure.

For the star network structure in microgrid, when they are connected to a constant load and a frequency-selective load, the change of the power line channel between the two smart meters is shown in Figure 12, where the green line is the change of channel model with a low impedance, the yellow line is the channel model with constant load, the red line is the change of the channel model with constant load and frequency selective load, and the blue line is the change of the channel model with constant load, frequency-selective load, and time-varying frequency-selective load.

For the bus network structure, when they are connected to a constant load and a frequency-selective load, the change of the power line channel between the two smart meters is shown in Figure 13, where the green line is the change of the channel model under constant load, the red line is the change of the channel model under constant load and frequency-selective load, and the blue line is the change of the channel model under constant load, frequency-selective load, and time-varying frequency-selective load.

It can be seen that from Figures 12 and 13, as the frequency of the carrier signal gradually increases, the attenuation in the channel gradually increases, and the more the parallel load is at the same carrier frequency, the more severe the attenuation of the main power line channel between the two smart meters' communication. When the power line carrier frequency is $30 \mathrm{MHz}$, with the random access of the load, the attenuation of the channel is very large, which has a great impact on communication quality. Besides, the more the load of the random access is, the greater the attenuation of the signal is. Therefore, in order to more effectively network the smart meter, it is necessary to consider the time variation of the channel when accessing the load for the star network structure and bus network structure.

Through the statistical analysis of the electricity consumption information of a certain community, it is found that when the electricity consumption of users increases, communication abnormalities are likely to occur, resulting in abnormal electricity consumption information collected, as shown in Figure 14. This is consistent with the simulation results in Figures 12 and 13. In Figure 14, (a) is the daily electricity consumption collected at different times at a certain collection point, (b) is the data of total electricity 


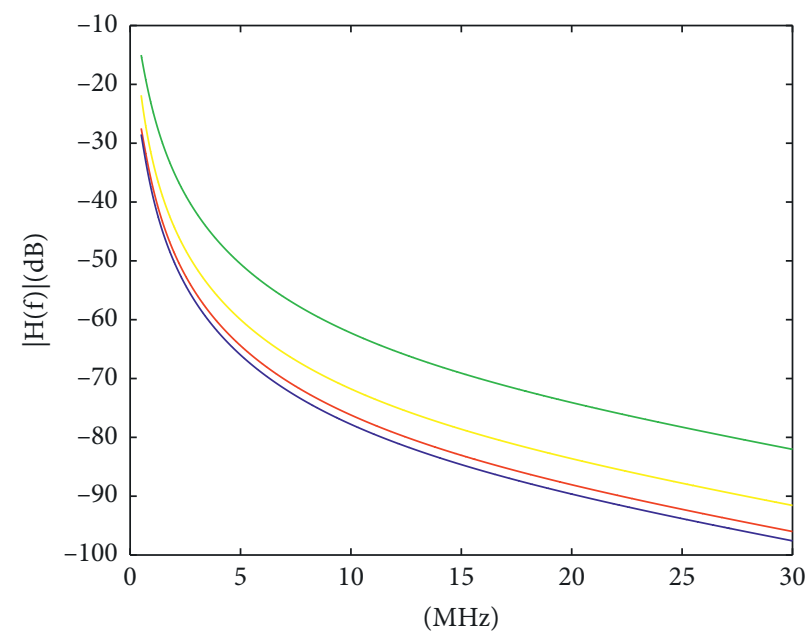

FIGURE 12: Channel changes in a star network structure.

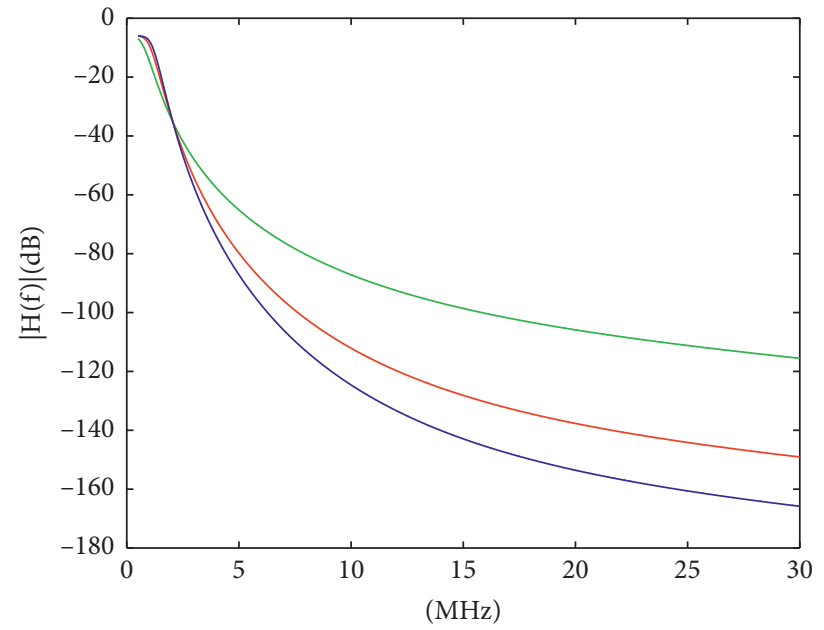

FIGURE 13: Channel changes in a bus-type network structure.

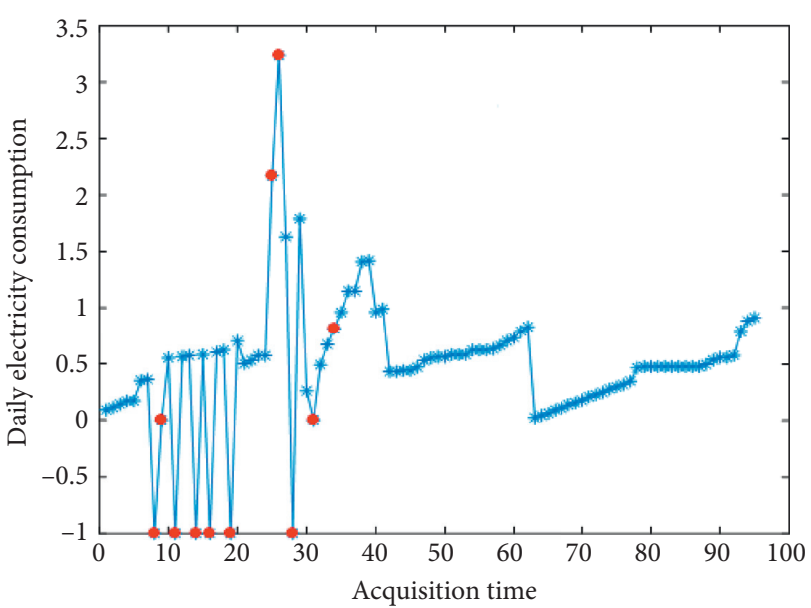

* Normal

- Abnormal

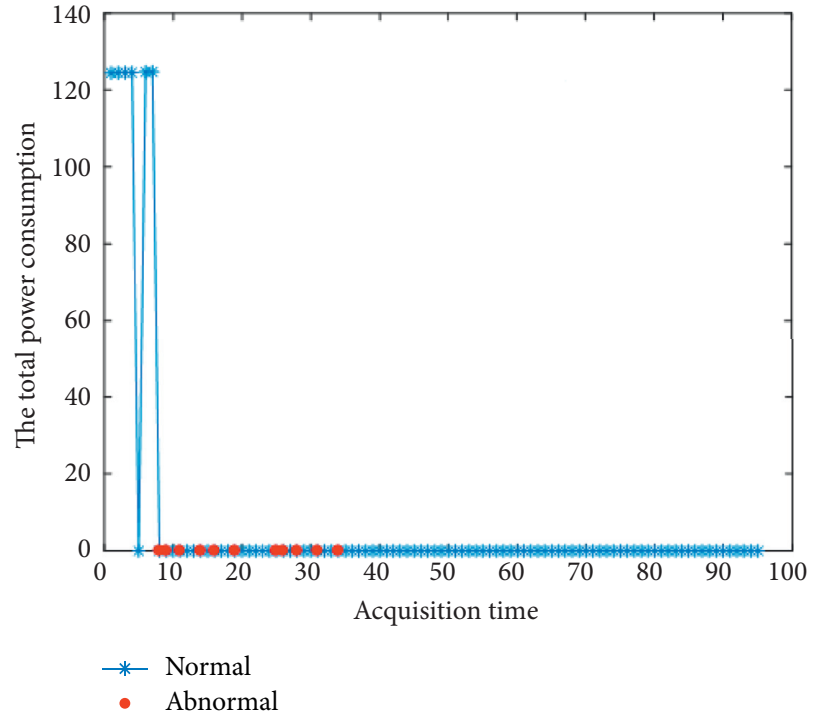

(b)

(a)

FIgURe 14: Continued. 


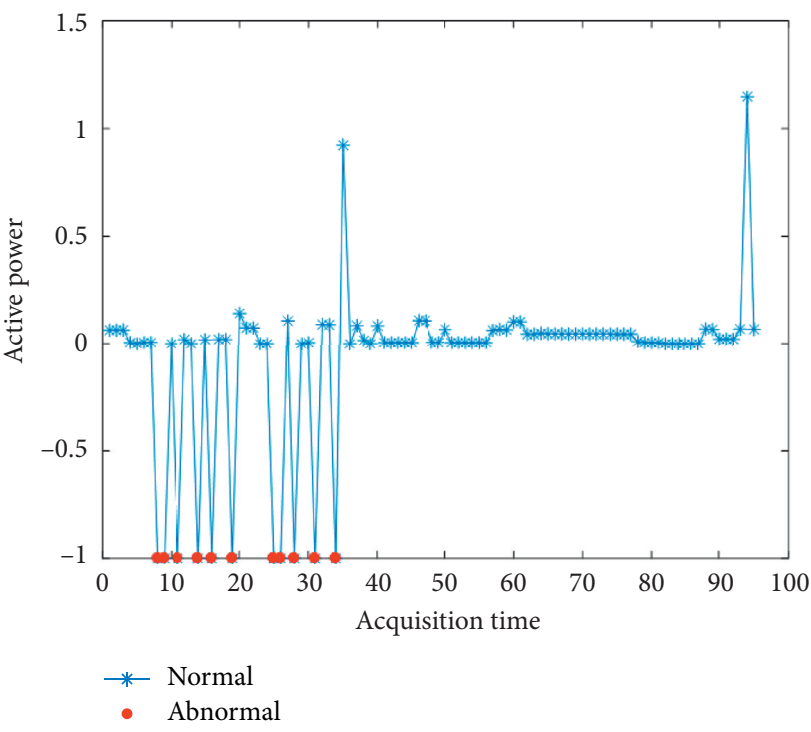

(c)

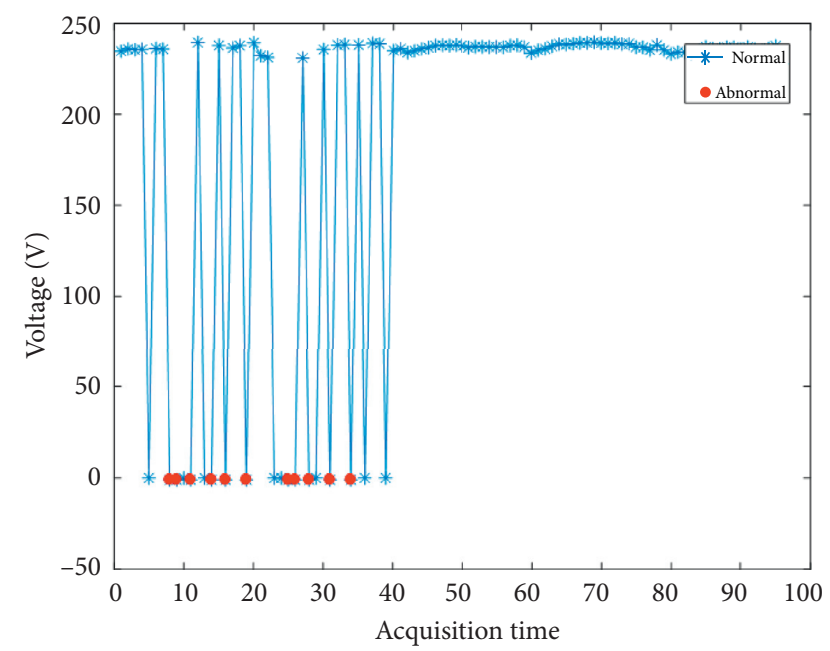

(e)

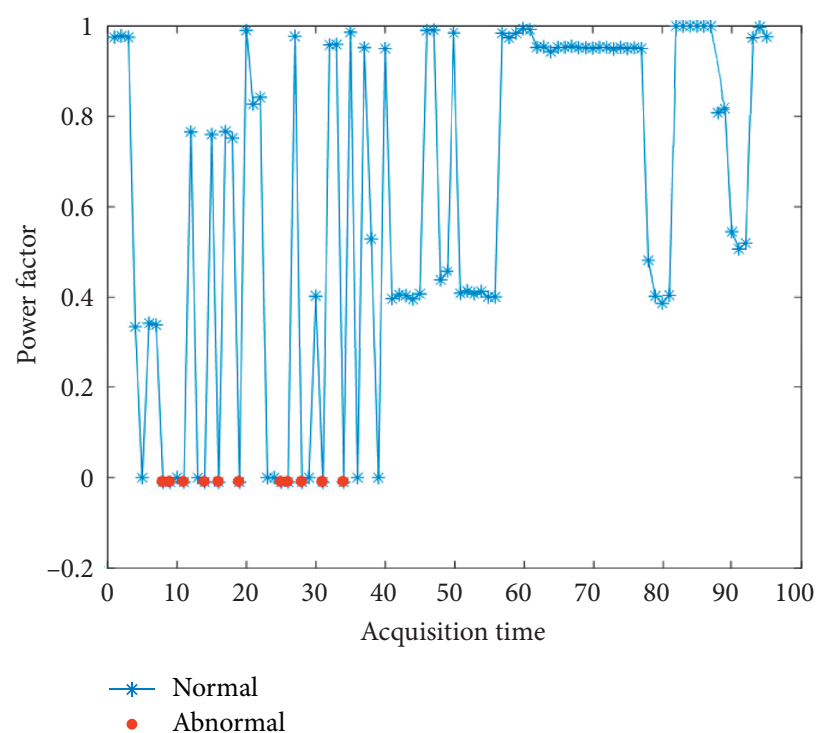

(d)

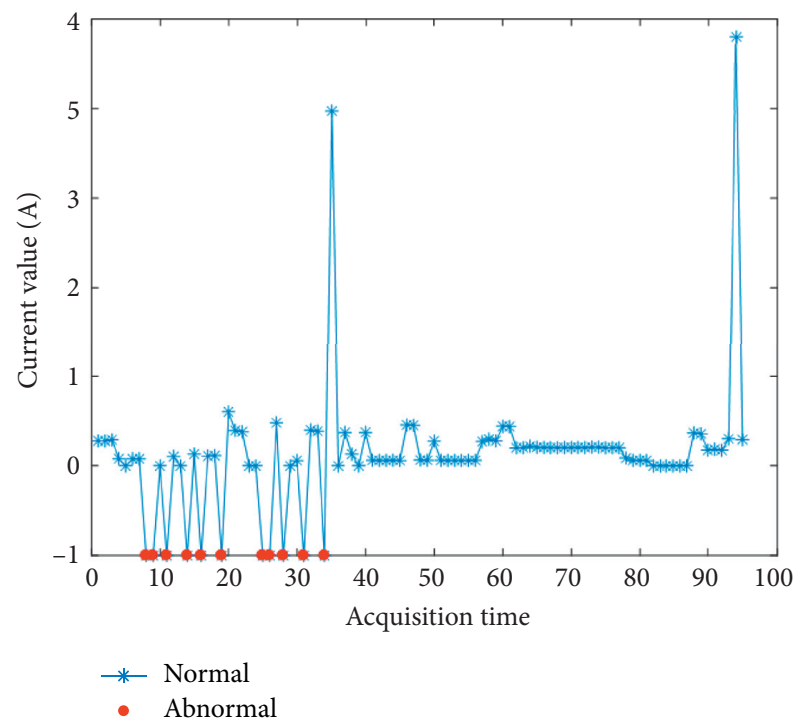

(f)

FIgURE 14: The normal state and abnormal state distribution of the data in the collection point.

consumption at different times, (c) is the active power value collected at different times, (d) is the power factor collected at different times, (e) is the voltage value collected at different times, and (f) is the current value collected at different times. The blue point is normal data; red dots mean anomaly data in the six diagrams of Figure 14.

\section{Analysis of Users' Electricity Usage Behavior}

According to the statistical characteristics of the users' electricity consumption behavior, this paper will use a relatively large electricity consumption period of time to characterize the time of the load access channel. That is, when the relay is dynamically selected, the power-increasing time is taken as a key factor. In the experimental area, the concentrator collects the information of the smart meter from 0 o'clock and collects it every 15 minutes, so the power consumption information of 96 moments is collected for each smart meter every day. To better mark the time point of collection, this paper uses the number to mark the collection time of the day, starting from 0 o'clock and adding 1 every fifteen minutes, the specific mark is shown in Table 2. According to the statistics of the users' electricity consumption in the test area, it is found that the users' electricity consumption is random, and the change of electricity consumption information varies from month to month. In order to analyze the change rule of the users' electricity consumption behavior, this paper takes August as an example to analyze the users' electricity consumption behavior. Figure 15 
TABLE 2: Digital markup for collecting time points.

\begin{tabular}{lccc}
\hline $00: 00$ & $00: 15$ & $00: 30$ & $00: 45$ \\
1 & 2 & 3 & 4 \\
\hline $01: 00$ & $01: 15$ & $01: 30$ & $01: 45$ \\
5 & 6 & 7 & 8 \\
\hline$\ldots$ & $\ldots$ & $\ldots$ & $\ldots$ \\
\hline $23: 00$ & $23: 15$ & $23: 30$ & $23: 45$ \\
\hline 93 & 94 & 95 & 96 \\
\hline
\end{tabular}

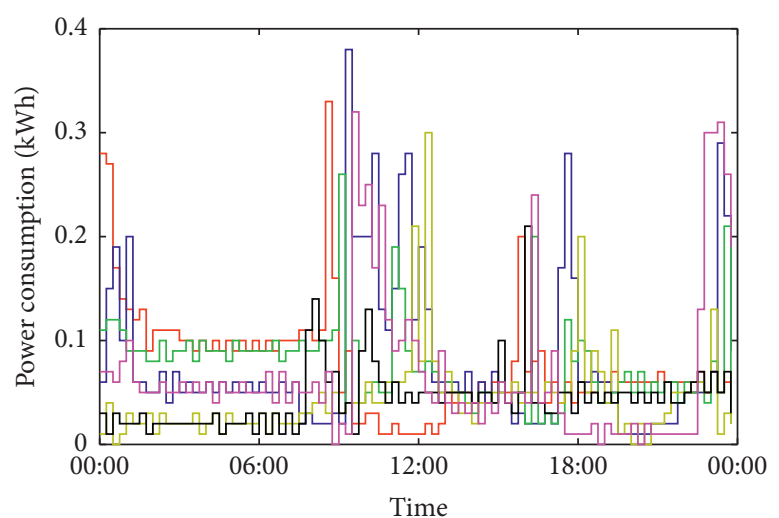

(a)

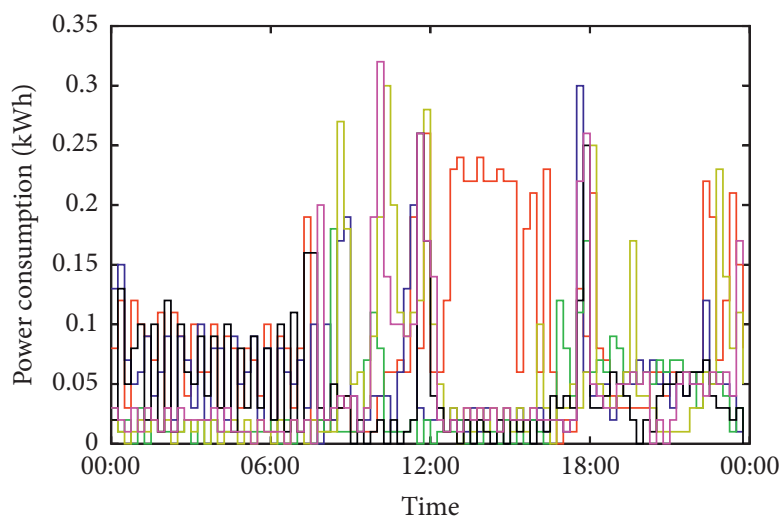

(c)

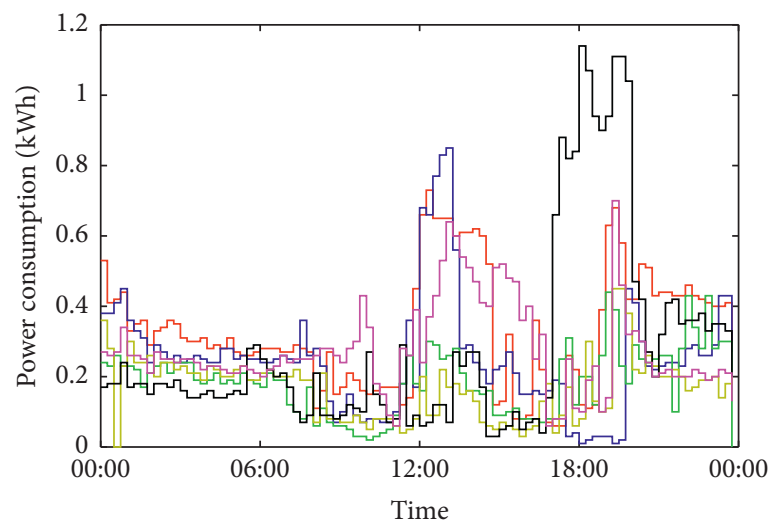

(e)

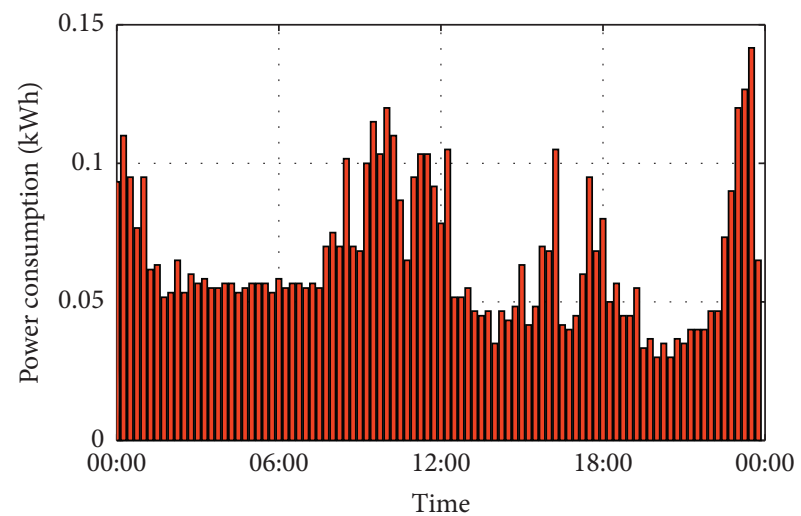

(b)

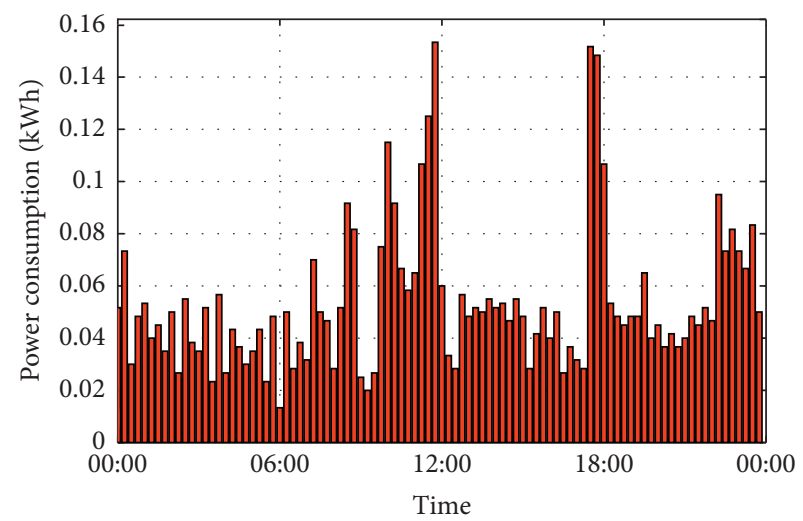

(d)

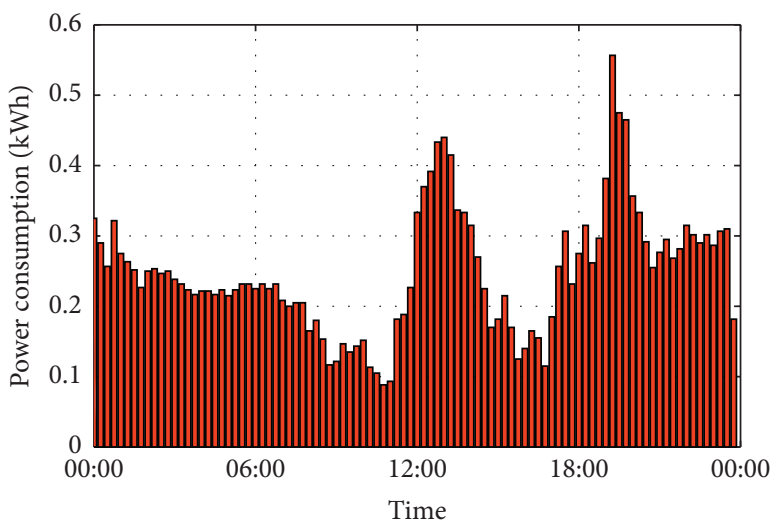

(f)

Figure 15: Continued. 


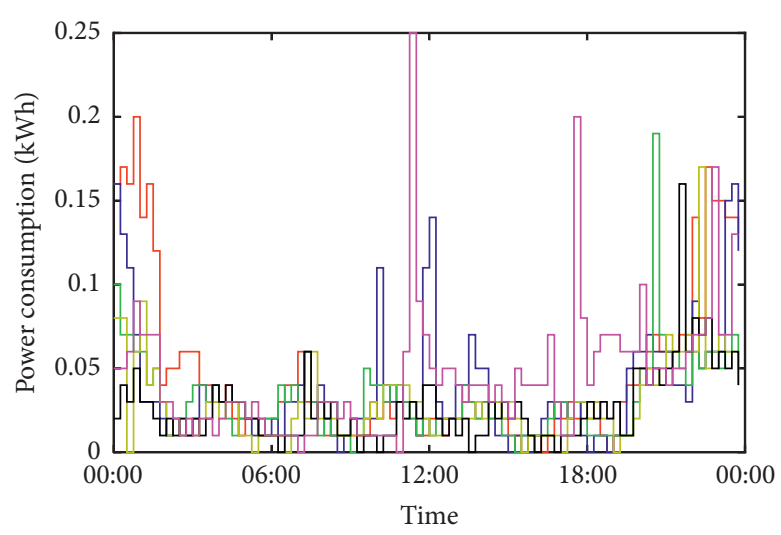

(g)

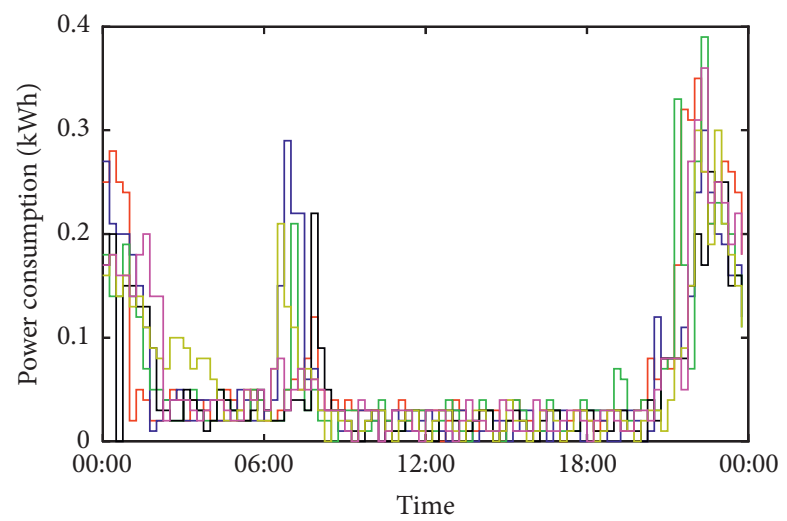

(i)

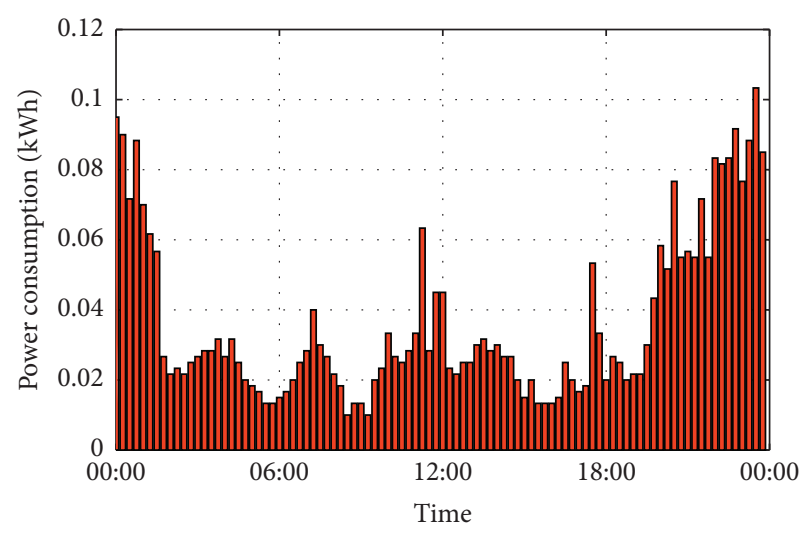

(h)

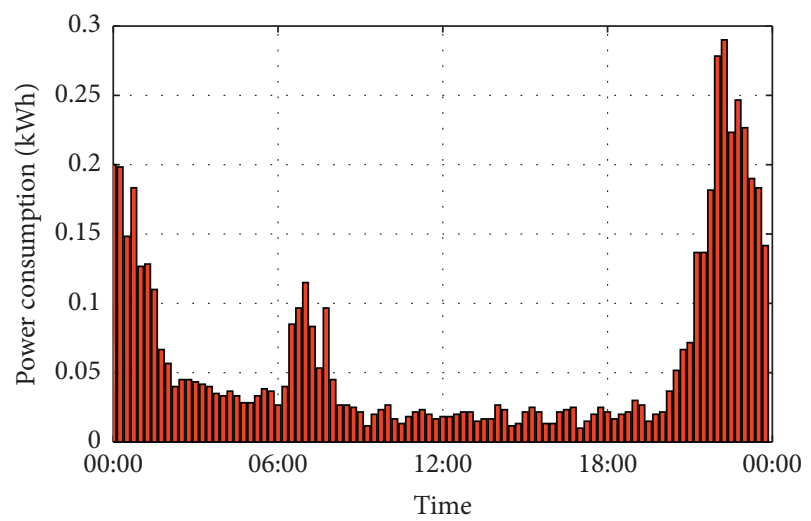

(j)

Figure 15: Change of electricity consumption for users in the test area.

shows the changes in the electricity consumption of some users randomly selected in August for 6 days and the average power consumption without considering vacant houses. Figure 15(a) is the change of electricity consumption of five representative users (excluding vacant rooms) in the experimental area for 6 days in August, and Figure 15(b) shows the changes in the average electricity consumption of these representative users at each collection time of the day in August. In Figure 15, each user's power consumption increase time is basically concentrated in one time period; for example, most users' power consumption will increase significantly at 12 o'clock.

In order to analyze the overall power consumption of users in the experimental area, this paper weighs the power consumption of all users in the cell, as shown in Figure 16. In Figure 16, households in the experimental area will have a significant increase in electricity consumption during certain time periods of the day, such as $00: 30-01: 30$ (marked by the numbers $3-7$ ); $11: 00-14: 30$ (marked by the numbers $5-59$ ); $18: 30-20: 00$ (marked by the numbers $75-81$ ); and $21: 00-23: 30$ (marked by the numbers $85-95$ ), and the time when the power consumption is increased is marked as shown in Table 2. Therefore, in the smart meter networking,

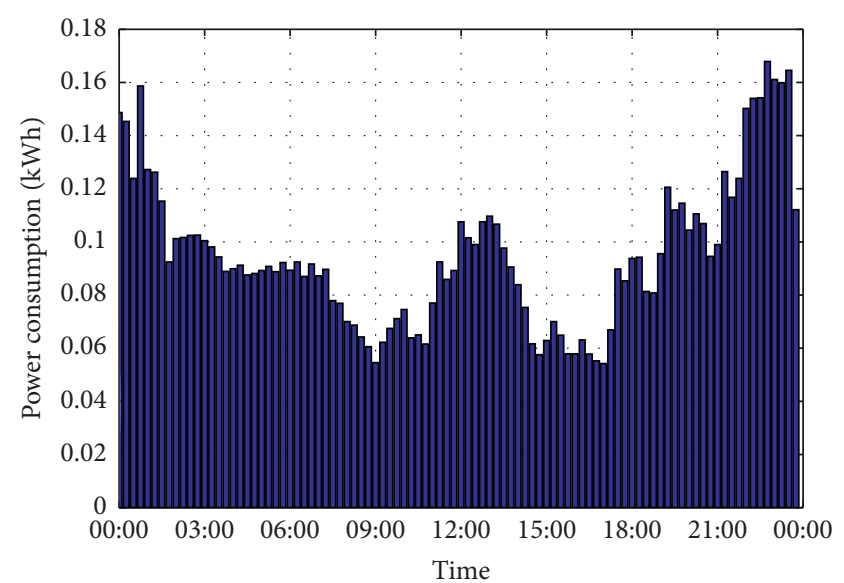

FIGURE 16: The average electricity consumption of a household in one day.

taking into account the time variability of the power line channel, when the collected information is abnormal, if the time point of collecting abnormal information is within a significantly increased time period, refer to the formula (17) below to dynamically select other communication paths. 


\section{Dynamic Relay}

According to the logical topology between the concentrator and the smart meters after the static relay selection, when the same smart meter communicates with multiple relays at the same time, a dynamic relay method is used to select the communication path. In the dynamic relay, the communication quality $Q_{d}$ is introduced. Taking the distance between two points in the experiment as the communication quality $Q_{d}$, the smaller the value, the better the communication quality.

The number of smart meters relayed by the $i$ relay to the upper relay is

$$
F_{i, j}=N_{a}+N_{b}
$$

where $N_{a}$ is the number of smart meters in the $j$-level subnetwork relayed by the $i$-number smart meter and $N_{b}$ is the lower subnet number of the $j$-level subnetwork relayed by the $i$-number smart meter.

When the same smart meter belongs to multiple relay communication ranges at the same time, the smart meter performs the optimal path selection according to the link optimization index, for example, the $i$-number smart meter relay to the $k$-number smart meter link optimization index:

$$
Y_{i, j-k}=\alpha Q_{d_{i, j-k}}+\beta F_{i, j}+\gamma \Delta_{k},
$$

where $Y_{i, j-k}$ is the link optimization index between the $i$ number relay and the $k$-number smart meter in the $j$-level subnetwork. $\alpha$ is the link optimization weighting coefficient; $\beta$ is the weighting factor of the number of smart meters that must be forwarded to the upper relay. $\Delta_{k}$ is the difference between the link optimization index of the optimal communication branch and the suboptimal communication link optimization index of the $k$-number smart meter. $\gamma$ is the weighting coefficient of data acquisition time when the $k$-number smart meter communicates with the $i$-number relay. Let $\alpha+\beta+\gamma=1, \alpha, \beta$, and $\gamma$ can be changed according to the actual situation; in the experiment, the $Y_{i, j-k}$ value is as small as possible. This paper chooses the smallest value of $Y_{i, j-k}$ as the optimal communication path, while closing the suboptimal communication path.

\section{Simulation Experiment}

7.1. The Establishment of the Initial Optimal Communication Link. When the smart meter belongs to multiple relay communication ranges at the same time, according to the idea of dynamic relay, the optimal communication link is calculated from the lowest level subnet in turn. In the simulation experiment, when the link optimization index is calculated for the first time, set the $\gamma=0, \alpha$, and $\beta$ values according to Table 3 .

Starting from the lowest-level subnetwork, the link optimization index is mainly determined by the communication quality. With the increase of the subnet level, the number of smart meters required by the superior relay and forwarding communication gradually increases, and its weight gradually increases. When the smart meter belongs to multiple relay communications at the same time, the calculation is performed according to the above parameter settings so as to establish an optimal communication path.

7.2. Dynamic Selection of Communication Branches. The smart meter communicates with the concentrator according to the initial communication branch. In the process of information acquisition, if the information collected at a certain time is empty or abnormal, the link optimization index is dynamically adjusted. According to the user's electricity information in the experimental area, the power consumption will increase obviously in time periods 00 : $30-01: 30 ; 11: 00-14: 30 ; 18: 00-20: 00$; and $21: 00-23: 00$. The effect of the time-varying load on the power line channel needs to be considered. This paper will set the dynamic relay link optimization parameters as is shown in Table 4. Among them, I refers to subnetwork parameters at each level of the original optimal communication branch during the power increase period; II to subnetwork parameters at all levels of the original suboptimal communication branch during the power increase period; III to subnetwork parameters of all levels of the original optimal communication branch in the nonelectricity increase period; and IV to subnetwork parameters of the original suboptimal communication branch in the nonelectricity increase period.

In the communication process between the concentrator and the smart meters, if the information collected at a certain moment suddenly becomes empty or abnormal, the link optimization index is recalculated for the smart meter according to Table 4, and the link with the smallest link optimization index is still selected as the optimal communication path. Figure 17 shows the optimal communication path after the dynamic relay at the start time, as shown by the yellow line in the figure. For example, when the collection of No. 25, No. 41, and No. 19 smart meters in the figure is empty, and the collection time is in $00: 30-01: 30 ; 11$ : $00-14: 30 ; 18: 00-20: 00$; and $21: 00-23: 00$, the No. 25 smart meter will communicate with No. 3 relay, the No. 41 smart meter will communicate with No. 49 relay, and the No. 19 smart meter will communicate with No. 48 relay, as shown by the red line in Figure 18. At the same time, the blue-dotted line indicates that the communication path is closed.

7.3. Results. When the smart meter was unable to communicate according to the original communication path due to the load, simulation experiments were performed on smart meters 25,41 , and 19 , and they were found that they can dynamically select other communication paths for communication as Figure 18 shows. For instance, the original communication path of smart meter 25 is 25-50-25-43-29-Con 1 ; the communication path after redynamically selected is 25-3-4-37-6-29-Con1; the original communication path of smart meter 41 is 41-3-4-37-6-29-Con1; the communication path after redynamically selected is 41-49-437-6-29-Con1; the original communication path of smart meter 19 is 19-9-11-10-8-39-Con 1 ; and the communication path after redynamically selected is 19-48-7-10-8-39-Con1, thereby improving the communication reliability 
TABLE 3: $\alpha$ and $\beta$ values of subnets at all levels.

\begin{tabular}{lll}
\hline \multirow{2}{*}{ First-level subnet } & $\alpha$ & 0.70 \\
& $\beta$ & 0.30 \\
\hline \multirow{2}{*}{ Second-level subnet } & $\alpha$ & 0.75 \\
& $\beta$ & 0.25 \\
\hline \multirow{2}{*}{ Third-level subnet } & $\alpha$ & 0.80 \\
\hline \multirow{2}{*}{ Fourth-level subnet } & $\beta$ & 0.20 \\
\hline \multirow{2}{*}{ Fifth-level subnet } & $\alpha$ & 0.90 \\
& $\beta$ & 0.10 \\
\hline
\end{tabular}

TABLe 4: $\alpha, \beta$, and $\gamma$ values of subnets at all levels.

\begin{tabular}{|c|c|c|c|c|c|}
\hline Communication branch & & $\mathrm{I}$ & II & III & IV \\
\hline \multirow{3}{*}{ First-level subnet } & $\alpha$ & 0.25 & 0.15 & 0.65 & 0.55 \\
\hline & $\beta$ & 0.25 & 0.25 & 0.25 & 0.25 \\
\hline & $\gamma$ & 0.5 & 0.6 & 0.1 & 0.2 \\
\hline \multirow{3}{*}{ Second-level subnet } & $\alpha$ & 0.3 & 0.2 & 0.4 & 0.6 \\
\hline & $\beta$ & 0.2 & 0.2 & 0.2 & 0.2 \\
\hline & $\gamma$ & 0.5 & 0.6 & 0.1 & 0.2 \\
\hline \multirow{3}{*}{ Third-level subnet } & $\alpha$ & 0.35 & 0.25 & 0.75 & 0.65 \\
\hline & $\beta$ & 0.15 & 0.15 & 0.15 & 0.15 \\
\hline & $\gamma$ & 0.5 & 0.6 & 0.1 & 0.2 \\
\hline \multirow{3}{*}{ Fourth-level subnet } & $\alpha$ & 0.4 & 0.3 & 0.8 & 0.7 \\
\hline & $\beta$ & 0.1 & 0.1 & 0.1 & 0.1 \\
\hline & $\gamma$ & 0.5 & 0.6 & 0.1 & 0.2 \\
\hline \multirow{3}{*}{ Fifth-level subnet } & $\alpha$ & 0.49 & 0.39 & 0.89 & 0.79 \\
\hline & $\beta$ & 0.01 & 0.01 & 0.01 & 0.01 \\
\hline & $\gamma$ & 0.5 & 0.6 & 0.1 & 0.2 \\
\hline
\end{tabular}

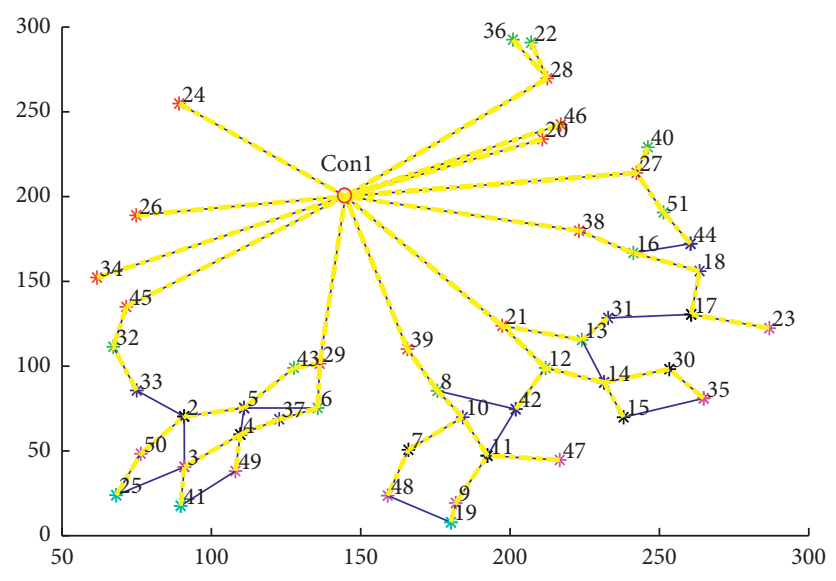

FIGURE 17: Smart meter communication path after dynamic selection of relay. 


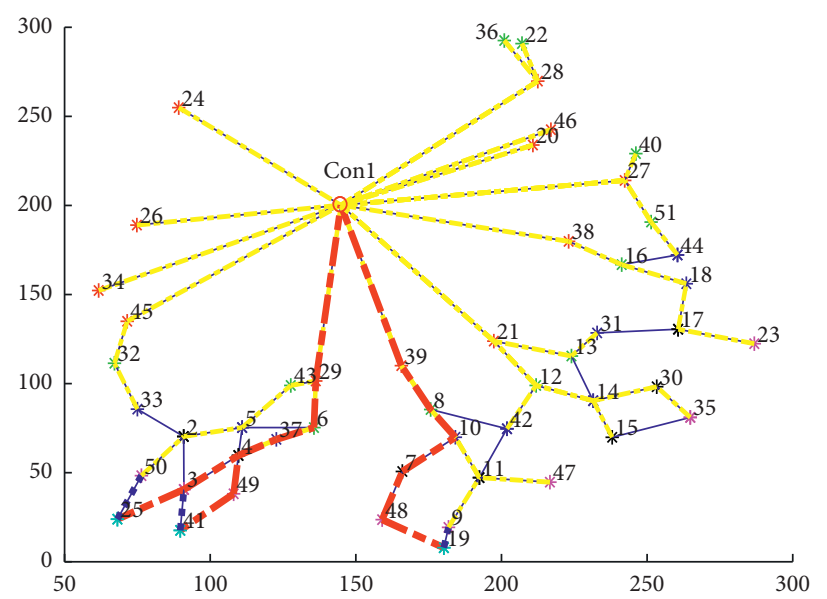

FIgURE 18: Smart meter communication path after redynamic selection.

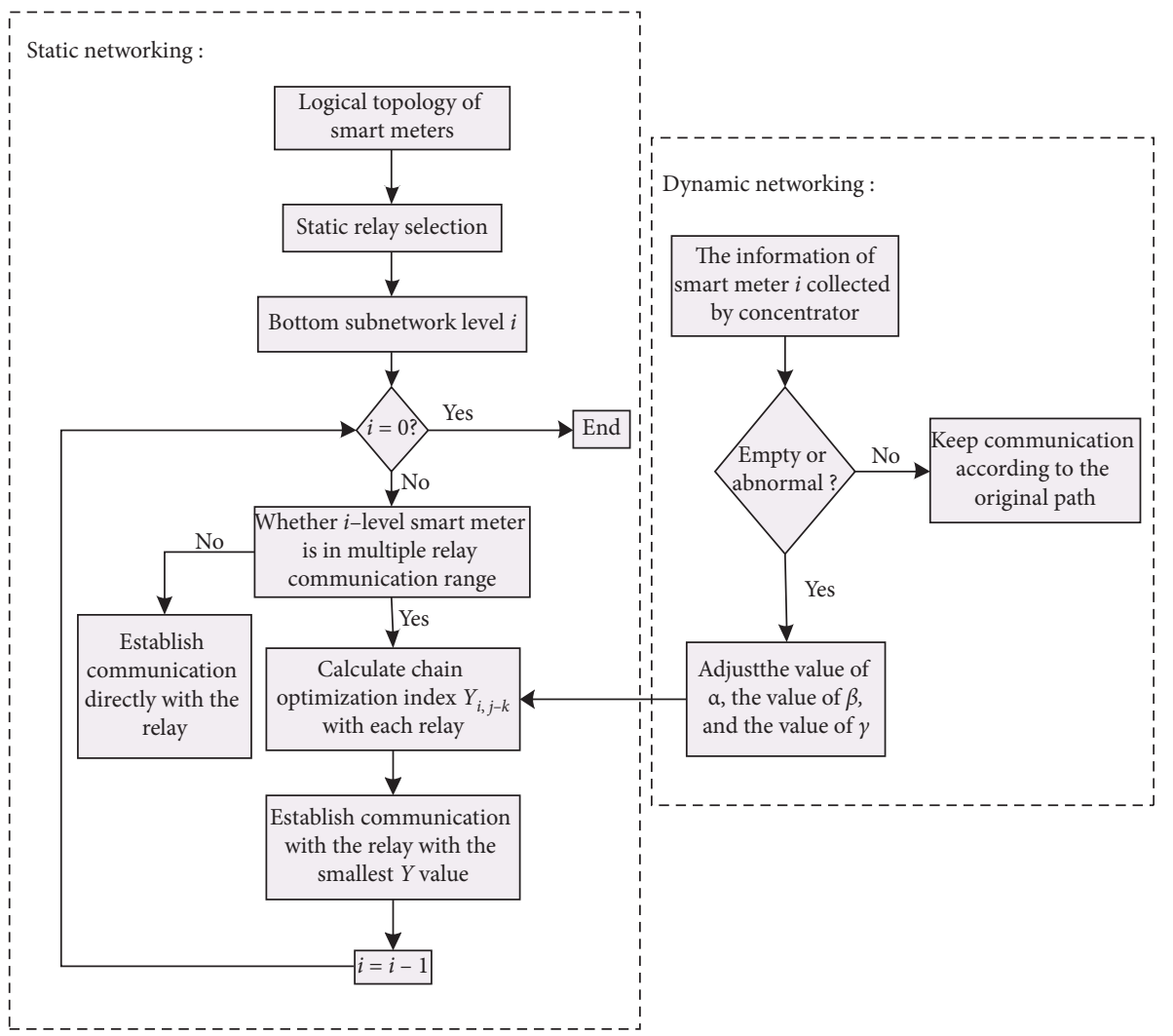

FIgUre 19: The overall static and dynamic networking flowchart.

performance of smart meters and concentrators. The reliability of intercommunication can ensure accurate collection of electricity information.

7.4. The Static and Dynamic Networking Flowchart. The overall flowchart of static and dynamic networking simulation experiment is shown in Figure 19, where the left panel is the static networking process, and the right panel is the dynamic networking process.

\section{Conclusion}

In order to improve the reliability of information acquisition in microgrid and the reliability of communication between the concentrator and the smart meters within the same low-voltage platform area, this paper adopts the idea of combining static and dynamic networking, effectively avoiding the communication failure caused by signal conflicts, and analyzes the changes of the power line channel when it suddenly added to the load. It is found that as the load increases, the attenuation of 
the high-frequency carrier signals in the power line channel cannot be ignored. Therefore, according to the influence of time-varying load on the power line, this paper analyzes the power consumption behavior of users. When the smart meter and the concentrator fail to communicate during the period when the user's power consumption increases, the optimal link optimization index of the smart meter will be recalculated with reference to the subnetwork parameter values in Table 4 and simulated by MATLAB. Through simulation, the smart meter can reselect the new branch to establish communication with the concentrator. Therefore, considering the communication distance and the number of relays forwarding, this paper considers the power line time-varying as the main factor in the smart meter networking process, which not only makes the selected communication path more reliable, but also puts forward a new idea for power line networking. However, there are still some problems in this paper that need to be further studied. Firstly, this paper only takes August as an example to carry out analysis and simulation experiments; the law of electricity consumption in other months will be studied in the future. Secondly, in terms of dynamic networking, some intelligent algorithms will be considered for networking research in the future. Finally, in order to realize the wide application of dynamic and static networking in practice, related hardware technologies will be studied in the future.

\section{Data Availability}

The data used in this paper come from the statistics of electricity consumption information, which has not been published publicly. This paper only takes these data as an example to illustrate the time-varying electricity consumption information.

\section{Conflicts of Interest}

The authors declare that they have no conflicts of interest regarding the publication of this paper.

\section{References}

[1] J. Lai, X. Yu, and A. Monti, "Stochastic distributed secondary control for ac microgrids via event triggered communication," IEEE Transactions on Smart Grid, vol. 11, no. 4, 2020.

[2] J. Lai and X. Lu, "Nonlinear mean-square power sharing control for ac microgrids under distributed event detection," IEEE Transactions on Industrial Informatics, vol. 17, no. 1, 2020.

[3] J. Lai, X. Lu, X. Yu, and A. Monti, "Cluster-oriented distributed cooperative control for multiple ac microgrids," IEEE Transactions on Industrial Informatics, vol. 15, no. 11, pp. 5906-5918, 2019.

[4] X. Jin, Y. Mu, H. Jia, J. Wu, T. Jiang, and X. Yu, "Dynamic economic dispatch of a hybrid energy microgrid considering building based virtual energy storage system," Applied Energy, vol. 194, pp. 386-398, 2017.

[5] J. Lai, H. Zhou, W. Hu, X. Lu, and L. Zhong, "Synchronization of hybrid microgrids with communication latency," Mathematical Problems in Engineering, vol. 2015, Article ID 586260, 10 pages, 2015.
[6] S. Tian and W. Luan, "Technical forms and key technologies on energy internet," Proceedings of the CSEE, vol. 35, no. 14, pp. 3482-3494, 2015.

[7] J. Lai, X. Lu, X. Yu, and A. Monti, "Stochastic distributed secondary control for ac microgrids via event-triggered communication," IEEE Transactions on Smart Grid, vol. 11, no. 4, pp. 2746-2759, 2020.

[8] D. D. Giustina, P. Ferrari, A. Flammini, S. Rinaldi, and E. Sisinni, "Automation of distribution grids with IEC 61850: a first approach using broadband power line communication," IEEE Transactions on Instrumentation and Measurement, vol. 62, no. 9, pp. 2372-2383, 2013.

[9] D. Mrozinski, "New approaches to automatic consumption meter reading in Germany," Computer Standards \& Interfaces, vol. 12, no. 1, pp. 43-52, 1991.

[10] A. Flammini, S. Rinaldi, and A. Vezzoli, "The sense of time in open metering system," in Proceedings of the 2011 IEEE International Conference on Smart Measurements for Future Grids (SMFG), pp. 22-27, Bologna, Italy, November 2011.

[11] J. M. Alonso, J. Ribas, J. J. D. Coz, A. J. Calleja, E. L. Corominas, and M. Rico-Secades, "Development of a distributive control scheme for fluorescent lighting based on LonWorks technology," IEEE Transactions on Industrial Electronics, vol. 47, no. 6, pp. 1253-1262, 2000.

[12] Y. Kan, Y. Jing, S. Liang et al., "An improved power line signaling technique based anti-islanding protection approach for distributed generation system," Proceedings of the CSEE, vol. 35, no. 13, pp. 3283-3291, 2015.

[13] S. Rinaldi, P. Ferrari, A. Flammini, M. Rizzi, E. Sisinni, and A. Vezzoli, "Performance analysis of power line communication in industrial power distribution network," Computer Standards \& Interfaces, vol. 42, pp. 9-16, 2015.

[14] J. LiZ. Jia et al., "Network construction method of cable antitheft network based on improved ant colony algorithm," Journal of Chongqing University of Technology (Natural Science), vol. 31, no. 12, pp. 160-165, 2017.

[15] M. Mishra and M. van Riet, "A channel model for power line communication using 4PSK technology for diagnosis: some lessons learned," International Journal of Electrical Power \& Energy Systems, vol. 95, no. 12, pp. 617-634, 2018.

[16] W. Cao and C. Yin, "Research on broadband MIMO power line communications model," Proceedings of the CSEE, vol. 37, no. 4, pp. 1136-1141, 2017.

[17] Q. Gao, Y. Wang, H. Yang, and N. Liu, "Low-voltage power line meter reading technology research based on multi-band spread spectrum," Power System Protection and Control, vol. 42, no. 5, pp. 136-141, 2014.

[18] M. Korki, C. Zhang, and H. Vu, "Performance evaluation of PRIME in smart grid," in Proceedings of the IEEE International Conference on Smart Grid Communications, pp. 294299, Vancouver, Canada, October 2013.

[19] M. Hoch, "Comparison of PLC G3 and PRIME," in Proceedigns of the 2013 IEEE International Symposium on Power Line Communications and its Applications, pp. 165-169, Udine, Italy, October 2011.

[20] J. Matanza, S. Alexandres, and C. Rodriguez-Morcillo, "Performance evaluation of two narrowband PLC systems: PRIME and G3," Computer Standards \& Interfaces, vol. 36, no. 1, pp. 198-208, 2013.

[21] A. Atayero, A. Alatishe, and Y. Ivanov, "Power line communication technologies: modeling and simulation of PRIME physical layer," in Proceedings of the World Congress on Engineering and Computer Science, pp. 931-936, San Francisco, CA, USA, October 2012. 
[22] M. Korki, N. Hosseinzadeh, and T. Moazzeni, "Performance evaluation of a narrowband power line communication for smart grid with noise reduction technique," IEEE Transactions on Consumer Electronics, vol. 57, no. 4, pp. 1598-1606, 2011.

[23] J. Domingo, S. Alexandres, and C. Rodriguez-Morcillo, "PRIME performance in power line communication channel," in Proceedings of the IEEE International Symposium on Power Line Communications and its Applications, pp. 159-164, Udine, Italy, July 2011.

[24] X. Liu and L. Zhang, "Performance analysis of power line communication network model based on spider web," in Proceedings of the ICPE 2011-ECCE Asia, pp. 953-959, Jeju, Korea, May 2011.

[25] X. Liu, Y. Cui, and D. Xu, "Performance optimization for low voltage power line communication," Electric Power Automation Equipment, vol. 37, no. 12, pp. 16-21, 2017.

[26] X. Liu, Y. Li, J. Wang, H. Zhu, and D. Xu, "Clustering-cobweb hybrid multipath blind Routing algorithm and communication protocol design for low-voltage power line communication," Transactions of China Electrotechnical Society, vol. 30, no. 1, pp. 337-345, 2015.

[27] Q. Gao, J. Y. Yu, P. H. J. Chong, P. L. So, and E. Gunawan, "Solutions for the "silent node" problem in an automatic meter reading system using power-line communications," IEEE Transactions on Power Delivery, vol. 23, no. 1, pp. 150-156, 2008.

[28] H. Su, J. Shi, Z. Liang et al., "Automatic transmission line path selection based on GIS and improved CA," Electric Power Automation Equipment, vol. 36, no. 12, pp. 109-114, 2016.

[29] Q. Ran, Y. Wu, and M. Qi, "Research on automatic routing method of low-voltage power line carrier network," Power System Protection and Control, vol. 39, no. 10, pp. 53-58, 2011.

[30] K. Chen and X. Hu, "Method of relay routing based on genetic adaptive ant colony system algorithm," Journal of Central South University (Science and Technology), vol. 44, no. 2, pp. 571-579, 2013.

[31] N. Xing, S. Zhang, Y. Shi, and S. Guo, "PLC-oriented access point location planning algorithm in smart-grid communication networks," China Communications, vol. 13, no. 9, pp. 91-102, 2016.

[32] L. Zhang, X. Liu, J. Qi et al., "Study of improved hierarchical ant colony routing algorithm for low-voltage power line communication," Transactions of China Electrotechnical Society, vol. 29, no. 2, pp. 318-324, 2014.

[33] J.-j. QI, X. U. Dian-guo, Y. Zhou, and L. I. U. Xiao-sheng, "Characteristics model and routing algorithm of power-line communications over low-voltage distributions," Transactions of China Electrotechnical Society, vol. 29, no. 16, pp. 56-62, 2009.

[34] F. Ni, P. H. Nguyen, J. F. G. Cobben, H. E. Van den Brom, and D. Zhao, "Three-phase state estimation in the mediumvoltage network with aggregated smart meter data," International Journal of Electrical Power \& Energy Systems, vol. 98, pp. 463-473, 2018.

[35] Y. Wang, X. U. E. Chen, and Y. Jiao, "Hierarchical classification PLC routing algorithm combinating static relay with dynamic relay in medium voltage distribution network," Electric Power Automation Equipment, vol. 37, no. 12, pp. 8-15, 2017.

[36] S. Martin, W. Liu, and K. Dostert, "On the impedance of lowvoltage distribution at frequencies up to $500 \mathrm{kHz}$," in Proceedings of the 2012 IEEE International Symposium on Power
Line Communications and Its Applications, pp. 30-34, Beijing, China, March 2012.

[37] J. Zhang, "Research on characteristics of low voltage power line communication channel," School of Aeronautics and Astronautics, vol. 40, no. 20, pp. 4-6, 2013.

[38] T. Zheng, X. Yang, and B. Zhang, "Measurement and research of impedance characteristics of low power networks within frequency band from $1 \mathrm{MHz}$ to $30 \mathrm{MHz}$," Power System Technology, vol. 29, no. 19, pp. 80-84, 2005.

[39] S. Galli and T. Banwell, "A novel approach to the modeling of the indoor power line channel-part II: transfer function and its properties," IEEE Transactions on Power Delivery, vol. 20, no. 3, pp. 1869-1878, 2005.

[40] W. Huang, J. Qi, N. Huang, and L. I. Yan, "Experiment and analysis of transmission line parameter for carrier wave communication over low-voltage power line," Electric Power Automation Equipment, vol. 28, no. 4, pp. 41-44, 2008.

[41] S. Galli and T. C. Banwell, "A deterministic frequency-domain model for the indoor power line transfer function," IEEE Journal on Selected Areas in Communications, vol. 24, no. 7, pp. 1304-1316, 2006. 